\title{
Two objections to wide-scoping
}

Daan Evers

Abstract: Wide-scopers argue that the detachment of intuitively false 'ought' claims from hypothetical imperatives is blocked because 'ought' takes wide, as opposed to narrow, scope. I present two arguments against this view. The first questions the premise that natural language conditionals are true just in case the antecedent is false. The second shows that intuitively false 'ought's can still be detached even with wide-scope readings. This weakens the motivation for widescoping.

Sometimes we make 'ought' statements conditional on some desire or goal: 'If you want $p$, then you ought to $X$. Such judgments are called hypothetical imperatives (because they are conditional on some presumed or "hypothesized" desire or goal). An example is:

(HI) If you want to kill Bill, then you ought to poison his drink. ${ }^{1}$

There is a famous problem connected with hypothetical imperatives. It is the Problem of Detachment (discussed in Greenspan 1975, Darwall 1983, Broome 1999 and Bedke 2009, among others). The problem is that from a hypothetical imperative supplemented with suitable premises, one can “detach” intuitively false 'ought' claims, as in the following example:

If you want to kill Bill, then you ought to poison his drink.

You want to kill Bill.

Therefore, you ought to poison his drink.

But, as Matthew Bedke puts it, 'you ought not poison Bill's drink. You ought to avoid him and seek counseling' (2009, p. 673).

In response to this problem, some philosophers have said that the 'ought' in hypothetical imperatives takes wide as opposed to narrow scope (Greenspan 1975,

${ }^{1}$ The example is from Bedke (2009). 
Darwall 1983, Broome 1999). That is to say, the correct way to (semi-)formalize (HI) is not:

$\mathrm{N}$ : If you want to kill Bill $\rightarrow \mathrm{O}$ (you poison his drink)

but rather:

$\mathrm{W}: \mathrm{O}($ If you want to kill Bill $\rightarrow$ you poison his drink).

This is supposed to solve the problem of detachment on the assumption that the truth conditions of 'if, then' constructions in natural language are like those of the material conditional. A material conditional 'if $p$, then $q$ ' is logically equivalent to the disjunction 'not- $p$ or $q$ '. This would solve the problem of detachment because $\mathrm{W}$ then reads:

$\mathrm{W}_{\mathrm{MC}}$ : $\mathrm{O}$ (either you do not want to kill Bill, or you poison his drink).

From $\mathrm{W}_{\mathrm{MC}}$ plus the premise that you want to kill Bill, it does not follow that you ought to poison Bill's drink:

'From the fact that you want to kill Bill it only follows that you should either reform your heinous end or poison Bill's drink.' (Bedke 2009, p. 677)

But I don't think that follows either. From $p$, it does not follow that not- $p$ or $q$, nor does it follow that $\mathrm{O}$ (not- $p$ or $q$ ). The latter does follow from $\mathrm{O}$ (if $p$, then $q$ ), provided 'if, then' is a material conditional.

I doubt that "wide-scoping" is a good solution to the problem of detachment for (at least) two reasons. The first is that the truth conditions of the material conditional are almost certainly not those of conditionals in natural language. Imagine meeting someone who says: 'If you put a sugarcube in water, then it will dissolve'. You ask: 'Why?', upon which you receive the following answer: 'Because you don't put a sugarcube in water'. That is a bad answer to your question.

However, it seems the wide-scope solution depends on the assumption that a natural language conditional is true if the antecedent is false. This dependency exists 
because what is embedded in the 'ought' (i.e. falls within its scope) is what has to be the case in order for the requirement (the 'ought' claim) to be satisfied. This is why one can think of satisfying requirements in terms of making various propositions true. For example: $A$ satisfies the requirement expressed by ' $A$ ought to $X$ ' by making the proposition that $A X$-es true (i.e. by $X$-ing). So one can satisfy a requirement like (HI) by making whatever falls withing the scope of 'ought' the case. Since wide-scopers claim that the 'ought' embeds a material conditional, they claim that you can satisfy (HI) by means of not wanting to kill Bill. However, this simply won't be so if the truth conditions of the natural language conditional are not identical to those of the material conditional. And I don't believe they are.

My second reason to doubt the wide-scope solution is that it equally allows us to detach unwanted 'ought's (although perhaps fewer). An adequate example of the deduction of unwanted 'ought's has to satisfy the following requirements:

(1) The hypothetical imperative is true.

(2) The consequent is impermissible.

(3) The antecedent is permissible.

I believe such examples can be found, and that the following is one: Jamie needs some medicine in order to survive. The most effective way to get it is to steal it from his neighbour. But it's the neighbour's property, and she needs it to survive as well. Now consider:

(J) If you want Jamie to survive, then you ought to steal the medicine.

Wide-scopers are committed to the claim that $(\mathrm{J})$, combined with the premise that you ought not to steal the medicine, allows us to deduce that you ought not to want Jamie to survive. But that is harsh. I ought not to steal the medicine, but I am not thereby required to be indifferent about Jamie's death. Nor do I necessarily have some reason to not want Jamie to survive (a much weaker claim). 
The above example can perhaps be disputed for the following reason: the example is based on the wrong reading of 'to want'. ${ }^{2}$ In the example, it is taken to mean 'to be in the mental state of desiring'. But it should be taken to mean: 'to aim for'. It sounds plausible that if

(1) it is impermissible to steal the medicine,

and

(2) stealing the medicine is a necessary means to Jamie's survival

then you should not aim for Jamie's survival either.

However, this response does not show the example to be inadequate, precisely because it depends on the assumption that stealing the medicine is a necessary means to Jamie's survival. This assumption is not part of the example and would have to be only if hypothetical imperatives are true only if the consequent states a necessary means. But this does not appear to be the case. Take Bernard Williams's example (2002):

(K) If you want to open the safe, then you ought to use a Phillips screwdriver.

Clearly, using a Phillips screwdriver is not a necessary means to opening the safe (we could also use some dynamite to blow a hole in it). But that doesn't make (K) false. So the truth of hypothetical imperatives depends more on the efficiency of the means than on their necessity. (K) would arguably not be true if using the Phillips screwdriver was not an efficient or the most efficient means to opening the safe. ${ }^{3}$

\footnotetext{
${ }^{2}$ This response was suggested to me by a member of the audience at a meeting of the Ockham Society in Oxford.

${ }^{3}$ It might be thought that hypothetical imperatives are true only if the consequent identifies the most efficient means. But I am not sure this is correct. It appears that considerations other than efficieny could go into the assessment of hypothetical imperatives, as long as these considerations are not incompatible with realizing the consequent. But I suppose one could argue that if considerations other than efficiency are brought to bear, then the hypothetical imperative is true only if the consequent
} 
To see why $(\mathrm{J})$ is still a good example, imagine there to be two means to Jamie's survival. One, the most efficient, is to steal the medicine. But the other less efficient means is to borrow money and buy it yourself. Since this is a permissible way of realizing Jamie's survival, it does not follow from $(J)$, plus the impermissibility of stealing the medicine, that you ought not to aim for Jamie's survival (one can aim for that by realizing the less efficient means). ${ }^{4}$

I take it that if the main motivation for wide-scope readings is the possibility of detaching undesirable 'ought's, then the fact that similarly undesirable 'ought's can be detached with wide-scope readings weakens that motivation. It also seems to me that the Problem of Detachment is better solved by a contextualist theory of 'ought' (like Evers forthcoming ${ }^{5}$ ), which makes the truth of 'ought' statements depend on salient rules or standards. In the case of (HI) and (J), the rules do not include moral (or any other) rules which forbid the realization of their consequents.

In my view, then, our resistance to the conclusion that you ought to poison Bill's drink is due to a shift in the rules relative to which we assess whether you ought to do it. We slide from a system which contains only rules of efficiency (and perhaps some others) to a system which contains moral rules. But if we keep in mind that you ought to poison Bill's drink only relative to rules of efficiency, then there is nothing wrong with detaching the conclusion that you ought to poison Bill's drink. After all, this conclusion is compatible with its being morally wrong for you to do so. ${ }^{6}$

\section{References}

Bedke, Matthew (2009). "The Iffiest Oughts: a Guise of Reasons Account of EndGiven Conditionals.” Ethics. 119(4): 672-698.

Broome, John (1999). “Normative Requirements.” Ratio. 12(4): 398-419.

\footnotetext{
identifies the most efficient means out of the class of means compatible with whatever other considerations are invoked.

4 Furthermore, one may wonder whether it is correct to restrict the possible antecedents for hypothetical imperatives to aimings only. What, then, is the right semantics for if-then constructions where the antecedent is correctly read in terms of desire? Should we not expect some uniformity?

${ }^{5}$ Although I now reject the theory of the weight of reasons developed in that paper.

${ }^{6}$ I would like to thank Ralph Wedgwood for helpful comments on an earlier draft of this paper.
} 
Darwall, Stephen (1983). Impartial Reason. Ithaca: Cornell University Press.

Evers, Daan (forthcoming). "The Standard-Relational Theory of 'Ought' and the Oughtistic Theory of Reasons", Australasian Journal of Philosophy.

Greenspan, Patricia (1975). "Conditional Oughts and Hypothetical Imperatives." The Journal of Philosophy. 72(10): 259-276.

Williams, Bernard (2002). “'Ought', 'Must', and the Needs of Morality.” Unpublished. 